\title{
The Study of University Students' Self-Concept
}

\author{
Xiaofeng Zhang \\ School of Sports Science, Qufu Normal University \\ 57 jing xian Street, Qufu, Shandong 273165, China \\ E-mail: zhangxiaofeng57@163.com \\ Chengzong Li (Corresponding author) \\ School of Education Science, Qufu Normal University \\ 57 jing xian Street, Qufu, Shandong 273165, China \\ E-mail:lichengzongaa@126.com
}

The research is financed by Creativity program subsidize project for postgraduate of ShanDong province.No.SDYC09032.

\begin{abstract}
Objective: Discussed the development of self-concept of university students. Methods: Used "Tennessee Self Concept Scale (TSCS)", measured 426 university student's self-concept status. Results: In the dimension of physical self-ethics, self-criticism, self-satisfaction, there were gender differences in university students' self-concept. Males' physical-self, self-criticism and self-satisfied were higher than females', while females' ethics were higher than males'. When referred to social self-concept, there were special differences. Students majored liberal arts had a higher score than the students of science. There were also differences in self-criticism, for example, the home location, whether only child or not, and the grades. College students also had differences in grade. Conclusion: College students' self-concept developed to a relatively stable level in the university. Except for a noticeable difference in gender, only a certain dimensions were noticeable in other demographic variables, while self-criticism had remarkable differences in most of them.
\end{abstract}

Keywords: University student, Self-concept

\section{Introduction}

Self-concept is a belief systems, it is the multi-faceted, multi-level cognitive and evaluation of oneself and their relationship with his surroundings. It's a core part of personality. W James considered that anything belong to oneself or related to oneself are all contents of oneself. China's study on self-concept started in the 1980s. There were quite a lot of descriptive and theoretical studies, however, the survey researches were not enough, and the scope was still not on a wide range. This study used cross-sectional comparison to survey the development of university students' self-concept.

\section{The Object and the Method}

\subsection{The Object}

The study investigated 441 university students, they were all from the same city and were divided into subpopulations and random samples were taken of each stratum, with 426 valid questionnaires were taken back. Among all the students, there were 221 males and 215 females: 168 liberal arts students and 258 science students; 183 freshmen, 113 sophomores, 89 juniors and 41 seniors.

\subsection{The Method}

"Tennessee Self Concept Scale" compiled by the U.S. psychologist H. Fitts, Tennessee in 1965, and Bangjie Lin, came from Taiwan, and revised the third edition in 1978, which had 70 topics and ten factors, including two dimensions of self-concept and the integrated status. The initiating structure included: self identity (ID), self-satisfaction (SA) and self-behavior (B); the content latitude including: physical self (PH), moral ethic self (ME), personal self (PRE), family self (FA) and social ego (SO); and the integrated status including: total positive(TOT) and self-criticism (SC). The first nine factors scored higher, the more positive self-concept was; while the higher the score the self-criticism had, the more negative self-concept was. The split-half reliability of the scale was among 0.925 to 0.945 .

The test made a class as a unit. The questionnaires were completed in the classroom within 20 minutes, and were recycled then and there. Removed the invalid questionnaires, 426 valid questionnaires were left. The recovery rate was 96.6\%, and the statistical software SPSS11.5 was used to process and analysis the data.

\section{Result analysis}

\subsection{The K-S test for self-concept}

In order to test whether university students'self-concept obeyed normal distribution or not, K-S test was used as 
non-parametric verify. The results was that university students' self-concept followed normal distribution $(Z=0.692, p=$ 0.724). Further test shown that male $(Z=0.488, p=0.971)$ and females $(Z=0.781, p=0.575)$, which also followed the normal distribution.

\subsection{Gender differences test in university students' self-concept}

Test results of gender differences as table 1 showed: physical self $(p<0.01)$, Moral-ethic self $(p<0.05)$, self-criticism ( $p$ $<0.01$ ) and self-satisfaction $(\mathrm{p}<0.001)$. Males' physical self, self-criticism and Self-satisfaction was higher than females', while the Moral-ethic self was lower.

\subsection{Profession differences in university students' self-concept}

Test results of profession differences as table 2 shown: there were differences in social-self $(\mathrm{p}<0.05)$, and liberal arts students scored were higher than the science students', other dimensions without any differences. As a whole, the urban students scored higher than rural students.

\subsection{Home location differences in university students' self-concept}

Test results of home location differences as table 3 shown: there were differences in the self-criticism $(\mathrm{p}<0.01)$. And urban students' scored higher than rural students', the other dimensions hadn't any differences.

\subsection{Only child or not in university students' self-concept}

Test results of only or not differences as table 4 shown: there were differences in self-criticism $(p<0.05)$, and the only-begotten students' scored higher than non-only-children, the other dimensions without any differences.

\subsection{Grade difference in college students' self-concept}

Test result of grade differences as the table 5 shown: there were differences between self-criticism $(\mathrm{p}<0.05)$ and self-satisfaction $(\mathrm{p}<0.05)$. Multiple-test results showed that in self-criticism, there were differences between the freshmen and sophomores $(\mathrm{p}<0.01)$, while to the other grades, there had no differences. The junior grades different from others in self-satisfaction, they were in the highest level.

\section{Discussions}

K-S test results showed that the sample followed the normal distribution. It represented the current status of college students' self-concept. The results of this study showed that college students' self-concept is in the middle and upper levels compared with the results of other studies that were published, indicating that college students' self-concept was positive on the whole. An adult's personality was fairly stable(McCrae \& Costa, 1994). And this stability signed that university students' pacifications of themselves was stable. In this period, self-concept had been basically stabilized, and they could easily accept the phenomenon that different situations could trigger different behavior and feelings. But important changes also taken place during this period. Specifically, there were higher scores in Moral-ethic self, family self and self-identity, which indicated that the moral ethic education for college students was quite successful. Most students had good moral standards, and majorities were quite satisfied with the background of their family. Their also had a strong sense of identification and self-esteem. Relatively speaking, college students had a lower evaluation on their physical self and personal self. They were not very satisfied with their performance and the self-regulated capability was weak. Thus, it was an important task of education to teach student to understand them, able to accept themselves, able to deal with their own strengths and weaknesses correctly and develop their self-control ability.

Self-concept differences of male and female students are mainly as the following aspects:

1) The males' physical self was higher than females'. First, may be males developed better motor skills. Second, it explained the physiological advantages that males had in this period. The social roles requested men to be powerful and career-driven; also, the females had a high expectation for male too.

2) When speak to Moral-ethic self, females' was better than males'. This was because the Chinese society had higher moral standards and request with women than men. Confucian moral ethic profoundly influenced on modern people's behavior. Society usually made more restrained demands for women on ethics and behavior. Compared to men, women suffer more restrict in ethics. Women didn't only have more self-discipline than men, they also had a better skill in introspection. Social and family lowered the expectations on women, which also declined women's society frivolousness and Psychological pressure. As a result, they could spend more time in communication. so male had lower self-evaluation in ethics than female, while at the same time, their ability to withstand setbacks was stronger, and they dare to face up to some weaknesses of their own.

3) Male university students scored higher than females' in self-criticism factors, and the difference was easily noticeable. It showed that male college students had lower appraisal on their own shortcomings and bad personality. On the one hand, they had the courage to criticize themselves; on the other hand, they had some problems of their own, and had a passive opinion of themselves, while females seemed to have higher demands on themselves. 
4) Male had higher self-satisfaction than female, which explained that male were more better at accept themselves, this maybe due to their physical superiority and the more conducive situation to male as the sociality developed.

5) There were no significant gender difference in behavior, personal self, social self, family self and identification. It shown that there were no gender differences in college students' self-acceptance at the present, the psychological-assess of themselves, the sense of the value and the acceptance when contact with others.

There was only professional difference in the Social-self. The professional difference in the self-concept was weak and reached a stable level in the university time.

There only was urban-rural difference in the Self-criticism. Urban students' self-criticism was higher than the rural students'. Perhaps because those rural students studied more diligently than the urban's. They had a feeling of not letting their parents and themselves down. Other dimensionalities had no significant differences, may be because education developed as the national economic development, and rural students had similar resources in education as the urban students. Also, market economic conditions emphasis competition of personal capacity, which laid the foundation for students' self-affirmation, So the rural students' appreciation for Status of self, their evaluation with the ability and value were all roughly the same as the urban students.

There were only-children differences in the self-criticism. Only-child had higher self-criticism. Perhaps because they didn't treasure the favorable conditions which they already had, when they made reflection with themselves and they felt sorry for the hard work and expectations of parents, so did high self-criticism arise.

self-satisfied of junior was higher than other grades, which indicated that after two years studied in the university, students had been able to understand what they need and fully understand themselves and satisfy with their behavior. But when it came to senior grade, probably due to the pressure of employment, their self-satisfied were lower than other grades and appeared lowest of self-concept.

\section{Conclusion}

4.1 Self-concept of university students developed relatively stable level during the college period.

4.2 There were noticeable gender differences in self-concept,while only a few differences in other demographic variables.

4.3 There were self-criticism differences in the majority of demographic variables, indicated that it is important for the university students'self-concept, which should be guided and controlled.

\section{References}

Hu, Weifang. (2004). A Study on the Self-concept of Students, Psychological Science, 1223-1225

Jian, Haishan.(2007). The relationship of College Students Self-concept and mental health, The Science Education Article Collects, 44--45

Lenny R. Vartanian. (2009)When the Body Defines the Self:Self-Concept Clarity,Internalization, and Body Image, Journal of Social and Clinical Psychology, 94-126

Tan, Wenjuan. (2009) Relationship between College Students'Self-concept and Parental Nurturing Styles, Journal of Nantong University (Education Sciences Edition), 57-61

Wan, Dezhi. (2007) The development of University Students' Self-concelf and Its' Relation to CoPing Style. Shandong University, 1-46

Table 1. Gender differences test for Self-concept $(\mathrm{M} \pm \mathrm{SD})$

\begin{tabular}{|l|l|l|l|}
\hline & \multicolumn{1}{|c|}{ male } & \multicolumn{1}{c|}{ female } & \multicolumn{1}{c|}{$\mathrm{t}$} \\
\hline physical self & $42.78 \pm 5.02$ & $41.2 \pm 4.41$ & $0.001^{* *}$ \\
\hline Moral-ethic self & $44.31 \pm 4.95$ & $45.26 \pm 4.32$ & $0.036^{*}$ \\
\hline personal self & $41.32 \pm 4.73$ & $40.7 \pm 4.15$ & 0.154 \\
\hline Family self & $46.51 \pm 6.38$ & $46.68 \pm 5.49$ & 0.766 \\
\hline Social self & $42.24 \pm 6.13$ & $41.58 \pm 5.49$ & 0.239 \\
\hline Self-criticism & $34.64 \pm 5.02$ & $33.31 \pm 4.17$ & $0.003^{* *}$ \\
\hline Self-identity & $91.56 \pm 8.80$ & $91.73 \pm 7.54$ & 0.83 \\
\hline Self-satisfaction & $81.45 \pm 8.29$ & $78.32 \pm 5.75$ & $0 * * *$ \\
\hline self-behavior & $78.7 \pm 9.07$ & $78.67 \pm 7.83$ & 0.896 \\
\hline total positive & $251.79 \pm 22.50$ & $248.73 \pm 17.78$ & 0.12 \\
\hline
\end{tabular}


Table 2. Profession differences of self-concept $(\mathrm{M} \pm \mathrm{SD})$

\begin{tabular}{|l|l|l|l|}
\hline & liberal arts students & science students & \multicolumn{1}{c|}{$\mathrm{t}$} \\
\hline physical self & $41.95 \pm 4.56$ & $42.0 \pm 4.93$ & 0.904 \\
\hline Moral-ethic self & $45.26 \pm 4.59$ & $44.48 \pm 4.70$ & 0.09 \\
\hline personal self & $41.28 \pm 4.49$ & $40.83 \pm 4.42$ & 0.308 \\
\hline Family self & $46.66 \pm 6.15$ & $46.55 \pm 5.81$ & 0.852 \\
\hline Social self & $42.77 \pm 5.67$ & $41.34 \pm 5.85$ & $0.013 *$ \\
\hline Self-criticism & $33.79 \pm 4.52$ & $34.09 \pm 4.75$ & 0.512 \\
\hline Self-identity & $92.25 \pm 8.03$ & $91.25 \pm 8.27$ & 0.219 \\
\hline Self-satisfaction & $80.07 \pm 7.17$ & $79.74 \pm 7.37$ & 0.647 \\
\hline self-behavior & $79.39 \pm 8.19$ & $78.3 \pm 8.61$ & 0.195 \\
\hline total positive & $251.71 \pm 19.81$ & $249.29 \pm 20.57$ & 0.23 \\
\hline
\end{tabular}

Table 3. Home location differences in self-concept $(\mathrm{M} \pm \mathrm{SD})$

\begin{tabular}{|l|l|l|l|}
\hline & urban students & rural students & \multicolumn{1}{c|}{$\mathrm{t}$} \\
\hline physical self & $42.08 \pm 4.62$ & $41.94 \pm 4.85$ & 0.784 \\
\hline Moral-ethic self & $44.75 \pm 4.56$ & $44.8 \pm 4.71$ & 0.918 \\
\hline personal self & $41.05 \pm 4.26$ & $40.99 \pm 4.53$ & 0.902 \\
\hline Family self & $46.88 \pm 6.12$ & $46.48 \pm 5.87$ & 0.526 \\
\hline Social self & $42.74 \pm 5.86$ & $41.56 \pm 5.78$ & 0.058 \\
\hline Self-criticism & $34.94 \pm 4.31$ & $33.57 \pm 4.74$ & $0.006^{* *}$ \\
\hline Self-identity & $92.66 \pm 8.15$ & $91.23 \pm 8.17$ & 0.101 \\
\hline Self-satisfaction & $80.78 \pm 7.06$ & $79.5 \pm 7.36$ & 0.098 \\
\hline self-behavior & $78.99 \pm 8.01$ & $78.62 \pm 8.64$ & 0.68 \\
\hline total positive & $252.44 \pm 19.90$ & $249.34 \pm 20.41$ & 0.153 \\
\hline
\end{tabular}

Table 4. Differences of only child or not in self-concept $(\mathrm{M} \pm \mathrm{SD})$

\begin{tabular}{|l|l|l|l|}
\hline & \multicolumn{1}{|c|}{ Only child } & Non-only child & \multicolumn{1}{c|}{$\mathrm{t}$} \\
\hline physical self & $41.46 \pm 4.30$ & $42.09 \pm 4.87$ & 0.31 \\
\hline Moral-ethic self & $44.25 \pm 4.71$ & $44.9 \pm 4.65$ & 0.285 \\
\hline personal self & $40.53 \pm 4.22$ & $41.1 \pm 4.49$ & 0.317 \\
\hline Family self & $46.57 \pm 6.54$ & $46.6 \pm 5.82$ & 0.97 \\
\hline Social self & $42.49 \pm 6.27$ & $41.79 \pm 5.73$ & 0.355 \\
\hline Self-criticism & $35.24 \pm 4.23$ & $33.71 \pm 4.70$ & $0.011 *$ \\
\hline Self-identity & $92.04 \pm 8.89$ & $91.56 \pm 8.04$ & 0.653 \\
\hline Self-satisfaction & $80.44 \pm 7.53$ & $79.75 \pm 7.24$ & 0.465 \\
\hline self-behavior & $78.04 \pm 8.09$ & $78.87 \pm 8.53$ & 0.451 \\
\hline total positive & $250.53 \pm 21.51$ & $250.19 \pm 20.06$ & 0.897 \\
\hline
\end{tabular}

Table 5. Grade difference in self-concept $(\mathrm{M} \pm \mathrm{SD})$

\begin{tabular}{|c|c|c|c|c|c|c|}
\hline & Freshmen & sophomores & Juniors & seniors & $\mathrm{t}$ & $\begin{array}{c}\text { Noticeable } \\
\text { differences project }\end{array}$ \\
\hline physical self & 41.85 & 41.53 & 42.75 & 42.12 & 0.324 & \\
\hline Moral-ethic self & 44.85 & 44.57 & 44.76 & 45.15 & 0.912 & \\
\hline personal self & 40.95 & 40.63 & 41.46 & 41.32 & 0.581 & \\
\hline Family self & 46.14 & 46.72 & 47.56 & 46.17 & 0.3 & \\
\hline Social self & 41.75 & 41.8 & 42.47 & 41.68 & 0.785 & \\
\hline Self-criticism & 33.36 & 34.88 & 34.26 & 33.56 & $0.044 *$ & $1<2 * *$ \\
\hline Self-identity & 91.58 & 91.21 & 91.96 & 92.44 & 0.841 & \\
\hline Self-satisfaction & 79.16 & 79.2 & 81.94 & 79 & $0.022 *$ & $1<3 * * ; 2<3 * ; 3>4 *$ \\
\hline self-behavior & 78.16 & 79.2 & 79.37 & 78.56 & 0.635 & \\
\hline total positive & 248.91 & 250.12 & 253.27 & 250 & 0.427 & \\
\hline
\end{tabular}

